\title{
O DESAFIO DA PARTICIPAÇÃO COMO REQUISITO DE SUSTENTALIDADE DE SOLUÇÕES DE SANEAMENTO - EXPERIÊNCIA EM UMA COMUNIDADE QUILOMBOLA NA ZONA DA MATA - MG
}

\author{
THE CHALLENGE OF PARTICIPATION AS A REQUIREMENT FOR THE \\ SUSTAINABILITY OF SANITATION SOLUTIONS - AN EXPERIENCE IN A \\ QUILOMBOLA COMMUNITY IN MINAS GERAIS STATE, BRAZIL
}

\author{
Lucas Alcantara Tótola ${ }^{(1)}$ \\ Engenheiro Ambiental pela Universidade Federal de Viçosa. Mestrando em Engenharia Civil no PPGEC/UFV. \\ Rafael Kopschitz Xavier Bastos ${ }^{(2)}$ \\ Engenheiro Civil pela Universidade Federal de Juiz de Fora. Doutorado e pós-doutorado em Public Health Engineering - \\ University of Leeds, UK. Professor titular da Universidade Federal de Viçosa, Departamento de Engenharia Civil. \\ Tarcísio Couto Carneiro Santos ${ }^{(3)}$ \\ Engenheiro Civil pela Universidade Federal de Viçosa. Mestrando em Engenharia Ambiental no PPGEAMB/UFLA. \\ Camila Conceição da Cruz ${ }^{(4)}$ \\ Graduanda em Engenharia Ambiental pela Universidade Federal de Viçosa. \\ Marcio Antonio Lopes Barsky ${ }^{(55)}$ \\ Graduando em Engenharia Ambiental pela Universidade Federal de Viçosa. \\ E-mail ${ }^{(1)}$ : lucastotola@hotmail.com

\section{RESUMO} \\ O presente trabalho traz relatos de um projeto de extensão em uma comunidade quilombola em Minas Gerais, em que o \\ objetivo de implantação de soluções descentralizadas de saneamento foi construído com o envolvimento da comunidade \\ em todo o processo, desde a seleção de tecnologias e a escolha dos beneficiários. Passados dois anos da implantação de \\ sistemas de esgotamento sanitário, procedeu-se à um levantamento do estado de manutenção / funcionamento dessas \\ unidades. Apresentam-se, a partir disso, reflexões acerca do processo participativo que permeou o projeto e da real \\ apropriação pela comunidade dos princípios de funcionamento das soluções implantadas e, por extensão, acerca da \\ sustentabilidade dessas soluções - ou seja, os alcances do projeto são discutidos sob a ótica de requisitos para a realização \\ dos direitos humanos à água e ao saneamento.
}

\begin{abstract}
This work presents findings of a project in a quilombola community in the state of Minas Gerais - Brazil, in which the objective of implementing decentralized sanitation solutions was built with the involvement of the community throughout the process, from the selection of technologies to the choice of beneficiaries. Two years after the implementation of sanitation systems, a survey was carried out on the state of maintenance/operation of those units. From this, reflections are presented on the participatory process that permeated the project and on the real appropriation by the community of the operating aspects of the implemented solutions and, by extension, on their sustainability - that is, the achievements of the project are discussed from the perspective of the realization of the human rights to water and sanitation.
\end{abstract}

Palavras-chave: Saneamento Rural. Participação comunitária. Tecnologias Sociais.

Key words: Rural Sanitation. Community Participation. Social Technologies.

\section{INTRODUÇÃO}

Soluções coletivas de abastecimento de água e de esgotamento sanitário são opções particularmente indicadas para áreas já com algum adensamento populacional. $\mathrm{Na}$ zona rural, onde muito frequentemente a população se distribui de maneira esparsa, soluções descentralizadas / individuais, podem se mostrar mais adequadas. Ocorre que nestes casos, via de regra, os usuários são responsáveis não somente pela implantação, mas também pela operação e manutenção dos sistemas. Assim, como indicado no Programa Nacional de Saneamento Rural (PNSR), torna-se necessário priorizar soluções de maior aceitabilidade (ou seja, compatíveis com as características socioeconômicas, ambientais e 
culturais das comunidades) e de fácil manejo pela população local. Para tanto, é preciso garantir a participação informada da população em todas as etapas de implantação de infraestrutura de saneamento, desde a concepção, "estimulando a adoção de tecnologias sociais e sustentáveis" (BRASIL, 2019). Porém, como pontuado no próprio PNSR, um dos principais obstáculos na provisão de serviços adequados no meio rural é a "ausência de estratégias que incentivem a participação social e o empoderamento" da população (BRASIL, 2019, p. 32), o que contribui para a incompletude da própria ideia de tecnologia social (DAGNINO, 2009). Em suma, a falta de participação pode resultar em escolhas que comprometam a aceitabilidade e, por conseguinte, a sustentabilidade das soluções, sendo estes (participação e sustentabilidade) dois dos princípios dos direitos humanos à água e ao saneamento (ALBUQUERQUE, 2014).

Nesta perspectiva, da participação informada e da sustentabilidade como requisitos para a realização plena dos direitos humanos à água e ao saneamento, apresenta-se neste trabalho um relato da experiência do projeto de extensão "Implementação de tecnologias sociais para preservação do meio ambiente e acesso à água na comunidade quilombola do Córrego do Meio. Em uma primeira fase do projeto (concluída) foram implantadas melhorias de esgotamento sanitário; em uma segunda (em curso) discutem-se melhorias de abastecimento de água. Ambas foram marcadas por processos participativos, de forma que as pessoas da comunidade se apropriassem de conhecimentos sobre sistemas descentralizados de abastecimento de água e de esgotamento sanitário e, ao fim, tomassem para si as decisões sobre o que implantar, onde e para quem. Entretanto, concluída a fase do projeto dedicada ao esgotamento sanitário, já se registram relatos de mau funcionamento em alguns sistemas e outros apresentam sérios problemas, ao ponto, inclusive, de terem sido desativados.

Diante do exposto, o presente trabalho tem como objetivo levantar reflexões acerca do processo participativo que permeou o projeto e da real apropriação pela comunidade dos princípios de funcionamento das soluções de esgotamento sanitário implantadas e, por extensão, acerca da sustentabilidade dessas soluções - um dos pilares das tecnologias sociais e um dos princípios dos direitos humanos à água e ao saneamento

\section{METODOLOGIA}

\subsection{Descrição da área de estudo}

A comunidade Córrego do Meio está localizada na zona rural de Airões, distrito de Paula Cândido, Zona da Mata - MG; possui 57 famílias, divididas espacialmente em grupamentos de casas ou vilas com graus variados de adensamento - em alguns casos com ocupação bem dispersa. Muitas pessoas da comunidade se ocupam em atividades tipicamente rurais, como a agricultura familiar ou como trabalhadores avulsos (por exemplo, na colheita do café); porém, outros trabalham na "cidade", principalmente em Viçosa - MG. Em sua maioria, a comunidade é formada por moradores fixos, que vivem em terras herdadas de seus antepassados, mas há também pessoas vindas de fora e proprietários que não residem na comunidade. Em 2015, ou seja, recentemente, a comunidade foi reconhecida como remanescente de quilombo. Trata-se, porém, de uma realidade heterogênea e complexa, em que convivem fortes influências do mundo urbano e características típicas de uma comunidade rural tradicional da zona da mata mineira, não necessariamente, ou exclusivamente, quilombola (MARQUES, 2016; CAPOBIANGO, 2019).

Em sua quase totalidade, os esgotos das residências são lançados diretamente nos córregos, ou são recolhidos em fossas rudimentares. Quanto ao abastecimento de água, em uma das vilas há um sistema coletivo, comunitário, suprido por um poço perfurado, profundo; outra, vizinha ao distrito de Airões, é abastecida por um sistema da Copasa, que atende também ao distrito; nas demais localidades são utilizados, principalmente, poços rasos escavados, em grande parte situados próximos aos córregos (contaminados por esgotos) e de outras fontes de contaminação, como as fossas rudimentares e criação de animais (suínos e bovinos). No âmbito do projeto aqui referido foram 
realizadas análises de qualidade da água, que revelaram elevados índices de contaminação, tanto no curso d'água principal que corta a comunidade, quanto em soluções individuais de abastecimento. $\mathrm{O}$ poder público é praticamente ausente e não há programas estruturados e ações contínuas de saneamento. Em resumo, as condições de saneamento são precárias e, por conseguinte, a comunidade convive com problemas ambientais e de saúde, nitidamente em não conformidade com os princípios dos direitos humanos à água e ao saneamento em várias de suas dimensões, denotando situação de discriminação, marginalização, estigmatização e desfavorecimento (ALBUQUERQUE, 2014).

\subsection{0 processo participativo}

Metodologicamente, o desenvolvimento do projeto teve por inspiração os ensinamentos de Freire (1996; 2018) e a "metodologia transversal" (CATALÃO, 2006), abordagens estas que superam a ideia de reprodução do conhecimento, em que o(a) educador(a) detém o saber (no caso, o saber técnico), do qual o(a) educando(a) é mero depositário(a). Ao contrário, busca-se conexão entre o saber técnico-científico e o saber fazer (ou "saber sensível" - FRONZA; ANDRADE; MOHEDANO, 2019), levando em conta o saber prévio do(a) treinando(a), que é requalificado, apropriado como um novo saber (MINISTÉRIO DAS CIDADES, 2007). Nesta perspectiva, foram desenvolvidas diversas atividades participativas e utilizados recursos didático-pedagógicos, com intuitos de, por etapas e nesta ordem: (i) reflexões sobre saneamento e suas relações com a saúde e o meio ambiente (ii) reconhecimento / problematização da situação de saneamento da comunidade, (iii) apropriação de conhecimentos técnicos sobre sistemas descentralizados de abastecimento de água e de esgotamento sanitário - princípios de funcionamento, aspectos construtivos, de operação e manutenção; (iv) identificação de soluções adequadas à realidade local; e (v) seleção das famílias a serem beneficiadas (CAPOBIANGO, 2019). Ou seja, na linha do proposto em Ministério das Cidades (2007) e Catalão (2006), se buscou criar um ambiente favorável à contextualização, à problematização, à elucidação de conflitos e à construção de consensos, por meio da mobilização e envolvimento da comunidade e da construção compartilhada de conhecimento. Cabe notar que este foi um processo longo e por etapas, particularmente na fase inicial dedicada ao esgotamento sanitário, em que se cumpriram atividades iniciais de estabelecimento de relações de confiança e de reconhecimento da realidade local (CAPOBIANGO, 2019).

As soluções de afastamento / tratamento de esgotos, bem como as de abastecimento / tratamento de água, foram selecionadas pela própria comunidade a partir de um leque inicial de opções e tendo em conta aspectos gerais e particularidades locais, tais como: adensamento populacional, relevo, tipo de solo, proximidade de cursos e fontes de água (no caso dos esgotos) ou de fontes de contaminação (no caso do abastecimento de água), custo, operação e manutenção. A seleção dos beneficiários também foi realizada pela própria comunidade, com base nos seguintes critérios: participação nas oficinas; condições socioeconômicas; situações de risco ambiental e de saúde (por exemplo, casas que lançam esgoto diretamente no córrego e famílias que consumem água não segura), e grupos vulneráveis, incluindo crianças menores de cinco anos e idosos acima de 60 anos.

\subsection{Implantação e avaliação da sustentabilidade das melhorias de saneamento}

À época da conclusão deste trabalho, as melhorias de abastecimento de água estavam por ser implantadas. Soluções de esgotamento sanitário foram instaladas em 18 residências em processo de semimutirão, com a participação dos moradores, de mão-de-obra local contratada (pedreiro e servente) e de estudantes voluntários - membros de grupos de extensão universitária (SANTOS, 2018). Passados dois anos, foi realizado um levantamento da situação de funcionamento, operação e manutenção dos sistemas de esgotos, incluindo inspeções de campo (com roteiros de inspeção específicos para cada tipo de sistema) e registros de relatos dos usuários, tendo também como referência um roteiro semiestruturado com perguntas orientadoras (cabe ressaltar que essas conversas não tiveram caráter de entrevista, se dando de maneira livre e com o objetivo único de completar / 
qualificar as observações da inspeção com informações sobre o funcionamento, operação e manutenção dos sistemas) (TÓTOLA, 2020).

\section{RESULTADOS ALCANÇADOS}

$\mathrm{Na}$ etapa de hierarquização das vantagens e desvantagens associadas pelos moradores a cada sistema de esgotamento sanitário, o fator identificado como de maior influência no processo de decisão foi a situação físico-ambiental do local de construção das "fossas", incluindo: facilidade de execução, relevo e potencial de contaminação da água. Como segundo fator em importância, os(as) participantes apontaram a demanda de operação e manutenção (CAPOBIANGO, 2019). Os sistemas de esgotamento sanitário priorizados pelos moradores foram: (i) Fossa sumidouro, para contribuição de todo o efluente doméstico, em residências em cota topográfica elevada, com restrições de disponibilidade de área no terreno e onde não houvesse risco de contaminação de fontes de água subterrânea; (ii) Tanque de evapotranspiração (TEvap), para contribuição apenas do vaso sanitário, em locais de lençol freático profundo; círculo de bananeira, para águas cinzas;(iii) Tanque de evapotranspiração (TEvap), para contribuição apenas do vaso sanitário, em locais próximos a córregos ou com lençol freático elevado; sistema alagado construído (SAC) para águas cinzas; (iv) Tanque séptico seguido de SAC para a contribuição total de todo efluente doméstico em situações semelhantes à anterior, mas em que não fosse possível a separação das águas cinzas e do vaso sanitário. No total, 18 sistemas foram implantados: nove TEvap, cinco TEvap + SAC, dois TS + SAC e dois sumidouros, contemplando 22 residências (SANTOS, 2018; TÓTOLA, 2020).

No caso do abastecimento de água, as soluções discutidas com a comunidade foram: desinfecção da água de poços rasos - cloradores por difusão (instalado no poço, com hipoclorito de cálcio); cloração em linha, com cloradores de pastilhas ou com o clorador simplificado "modelo Funasa" (com hipoclorito de cálcio), filtros domiciliares de cerâmica, caixas d'água (reservatórios domiciliares) e perfuração de poços profundos. É importante observar que, por limitação orçamentária, a opção pelos poços restringiria consideravelmente o número de residências a serem atendidas; mas esta foi a decisão majoritária, em muito orientadas por critérios de demandas cotidianas de operação e manutenção no caso dos cloradores, mas também pela sustentabilidade representada pela opção pelos poços (ainda que este termo não tenha sido empregado pelas pessoas da comunidade). Ao final, cinco residências foram priorizadas para serem contempladas com poços, quatro com cloradores de pastilha, e seis com caixa d'água e/ou filtro.

Como resultado da avaliação das condições de operação e manutenção dos sistemas de esgotamento sanitário, constatou-se que: (i) TEvap - a maioria (11 unidades) se encontrava em boas condições de funcionamento, ou apresentava problemas relativamente simples de serem resolvidos, causados por detalhes construtivos ou por operação / manutenção inadequada, como, por exemplo, recebimento de água de enxurrada, vazamentos (dois sistemas) e falta de vegetação (três sistemas) - este último aspecto é de suma importância, pois a cobertura vegetal é parte fundamental do sistema; apenas duas unidades apresentavam problemas mais críticos, causados, provavelmente por problemas construtivos (retorno de esgotos), sendo que uma foi desativada; (ii) SAC - dos sete sistemas instalados, apenas dois apresentavam boas condições de funcionamento e um terceiro apresentou problemas simples - recebimento de água de enxurrada e não se encontrava vegetado; os demais apresentaram problemas mais sérios devido à colmatação do meio suporte, em geral como resultado de operação / manutenção inadequada (limpeza da caixa de gordura e dos tubos de distribuição) e, ou de falhas construtivas (recebimento de águas de enxurrada); por outro lado, de acordo com relatos dos(as) usuários(as), as unidades em bom estado de funcionamento recebiam atenção frequente em termos de operação e manutenção; (iii) TS - das duas unidades instaladas, uma (que precede um SAC) se encontrava desativada por problemas de funcionamento - falhas construtivas e retorno de mau cheiro no banheiro; (iv) sumidouros - as duas unidades instaladas na comunidade se encontravam em boas condições, em bom funcionamento (TÓTOLA, 2020). 
No que tange ao processo participativo importa destacar o protagonismo das mulheres, a começar por um grupo que desde o início mostrou proatividade e passou a colaborar no planejamento e execução de todas as atividades do projeto - mulheres com forte liderança na comunidade, que participaram ativamente no processo de reconhecimento quilombola e que permanecem atuantes na Associação Comunidade Quilombola do Córrego do Meio (CAPOBIANGO, 2019). Como bem pontuado por Macêdo (2018), as mulheres negras quilombolas são também as propulsoras das lutas por regularização territorial e conservação da memória coletiva. Mas, a participação predominante das mulheres se deu para além desse grupo de lideranças. De acordo com o relato de uma dessas lideranças: "essas reuniões sobram mais para as mulheres, é muito difícil ver os homens a frente no projeto, estar acompanhando e lutando por isso aqui. A doença, se chegar na sua casa, é a mãe que sempre leva o filho no hospital. A batalha da casa é da mulher". Neste depoimento dois aspectos merecem atenção: o envolvimento majoritário das mulheres no projeto (leia-se, comprometimento em processos coletivos) e as responsabilidades do trabalho doméstico que sobre elas recaem, incluindo-se aí tarefas de manutenção das unidades domiciliares de saneamento - como discutido por Silva (2017).

Em ambas as fases do projeto (esgotos e água), ao final das etapas de seleção de tecnologias, a percepção era que a proposta pedagógica tinha sido alcançada, isto é: os recursos pedagógicometodológicos utilizados tinham logrado provocar a troca efetiva de saberes técnico e popular, (CAPOBIANGO, 2019); ou nas palavras de Fronza; Andrade e Mohedano (2019), "os participantes se encontravam com a conexão humana e o saber sensivel ativos para apreender novos conceitos cognoscíveis, dando lugar à fixação do saber técnico, ao engajamento e ao empoderamento que favorecem o desencadear da transformação esperada". Mas, recorrendo à questão levantada por estes mesmos autores: "a indução ou estimulação para novos comportamentos podem ser alcançadas de forma pontual sem implicar transformações significativas no sentido da construção de novo padrão social; e como vencer este desafio e saber se os estímulos foram suficientes para uma transformação verdadeira e pertinente?"

Do levantamento da situação dos sistemas de esgotamento sanitário implantados na comunidade notase que, em geral, os problemas de mau funcionamento estão relacionados a falhas construtivas e, ou operação / manutenção inadequadas. Chama atenção o fato que alguns sistemas (SAC e TEvap) apresentavam sérios problemas, ao ponto, inclusive, de terem sido desativados. Isso levanta questionamentos a respeito da sustentabilidade de soluções que dependem de manutenção frequente por parte dos usuários - principalmente no caso dos SAC. Mas suscita também reflexões acerca da real apropriação pela comunidade (ou de parte da comunidade) dos princípios de funcionamento desses sistemas de esgotamento sanitário, pois alguns SAC e TEvap sequer tinham sido vegetados. Ou ainda que a real demanda de operação e manutenção desses sistemas não tenha sido adequadamente dimensionada por ambas as partes (educadores e educandos). Mas essa discussão não pode ignorar a dimensão de gênero, em uma realidade em que a tarefa de manutenção desses sistemas recai sobre as mulheres, já tão sobrecarregadas nos afazeres domésticos e, não raramente, também com trabalho remunerado fora do domicílio (SILVA, 2017).

Por outro lado, em que pesem os problemas levantados, é preciso também registrar que a maioria dos sistemas se encontrava em pleno e bom funcionamento, o que sugere efetividade do processo participativo. Neste sentido, cabe notar que o principal critério de escolha das famílias a serem contempladas foi justamente a participação ao longo de todo o processo. Logo, em tese, as pessoas contempladas com melhorias de saneamento seriam aquelas que tiveram maiores oportunidades de apropriação do conhecimento técnico - o que parece se ter confirmado.

É preciso, por fim, acrescentar à discussão o elemento que a mobilização e a participação social são, em si, desafios, quanto mais em uma realidade complexa como é a da Comunidade Córrego do Meio e já marcada por certa descrença em decorrência da mencionada situação de marginalização e desfavorecimento. Ademais, como já referido, o processo aqui relatado tem se dado de forma um 
tanto morosa e prolongada, o que, inevitavelmente traz riscos de dispersão e desmobilização. Todavia, as estratégias de mobilização utilizadas e a relação de confiança estabelecida com a comunidade têm dado conta de superar estes obstáculos (CAPOBIANGO, 2019; SANTOS, 2018).

\section{CONCLUSÕES}

O relato desta experiência permite os seguintes destaques: (i) por mais que a mobilização social e a participação se apresentem como desafios, são elementos indispensáveis para que se cumpram os intuitos da sustentabilidade (eficácia e perenidade) das intervenções - princípios caros à realização dos direitos humanos à água e ao saneamento; (ii) ainda que aparentemente a apropriação do conhecimento técnico tenha se dado de forma desigual, o saldo é positivo, na medida em que a maioria dos sistemas de esgotamento sanitário se encontrava em boas condições de funcionamento e com a devida atenção em termos de operação e manutenção; (iii) não obstante, os resultados evidenciam a importância dos cuidados construtivos, pois falhas de execução podem contribuir para a desqualificação de uma tecnologia; (iv) revela-se ainda a importância do fator operação e manutenção de soluções individuais de saneamento - priorizado pelas próprias pessoas da comunidade como critério de seleção de tecnologias - e que, portanto, merecem atenção redobrada no processo de construção compartilhada do conhecimento; (v) por fim, evidencia-se a relevância de se contemplar a dimensão de gênero na escolha de soluções individuais de saneamento no meio rural

\section{AGRADECIMENTOS}

Aos órgãos financiadores do projeto: Secretaria de Estado de Minas Gerais de Desenvolvimento Agrário; Ministério Público do Trabalho e Vara da Justiça do Trabalho de Ouro Preto.

\section{REFERÊNCIAS}

ALBUQUERQUE, C. Manual prático para a realização dos direitos humanos à água e ao saneamento pela relatora especial da ONU, Catarina de Albuquerque. Cap. 4: Princípios. Portugal: OHCHR, 2014. BRASIL. Ministério da Saúde. Fundação Nacional de Saúde. Programa Nacional de Saneamento Rural. Brasília: Funasa, 2019.

CAPOBIANGO, G. V. Reflexões sobre o processo de seleção de soluções de saneamento em uma comunidade quilombola na Zona da Mata - MG: Participação e percepção da comunidade, diálogos entre os saberes técnico e popular. Dissertação (Mestrado em Engenharia Civil), 2019, 152f. Departamento de Engenharia Civil, Universidade Federal de Viçosa, Viçosa, 2019.

CATALÃO, V. M. L. e RODRIGUES, M. S. (Orgs). Água como matriz ecopedagógica: um projeto a muitas mãos. Brasília: Departamento de Ecologia da Universidade de Brasília, p.82-94, 2006.

DAGNINO, R. (org.) Tecnologia social: ferramenta para construir outra sociedade. Campinas: Unicamp, 2009. $95 \mathrm{p}$.

FREIRE, P. Pedagogia da Autonomia: saberes necessários à prática educativa. Rio de Janeiro: Paz e Terra, 1996.

Extensão ou Comunicação? $19^{\mathrm{a}}$ ed. Rio de Janeiro: Paz e Terra, p.128, 2018.

MACÊDO, M. L. de F. O protagonismo feminino: Comunidade Quilombola Sítio Arruda em Araripe Ceará. Tese (Doutorado em História), 2018. 215f. Universidade do Vale do Rio dos Sinos. São Leopoldo, 2018.

FRONZA, E. E.; ADRADE, I. T.; MOHEDANO, R. A. Núcleo de Educação Ambiental da UFSC e o Programa de Formação Continuada de Educadoras e Educadores Ambientais para uma Cultura da Sustentabilidade. Revista Eletrônica do Mestrado em Educação Ambiental. Rio Grande: v.6, n.2, p.253-274, 2019.

MARQUES, P. D. A. Os processos do processo: (re)apropriações e (re)ssignificações dos direitos pela comunidade quilombola de Córrego do Meio/MG.. 2016. Dissertação (Mestrado em Extensão Rural) Universidade Federal de Viçosa, Viçosa, MG, 2016. 

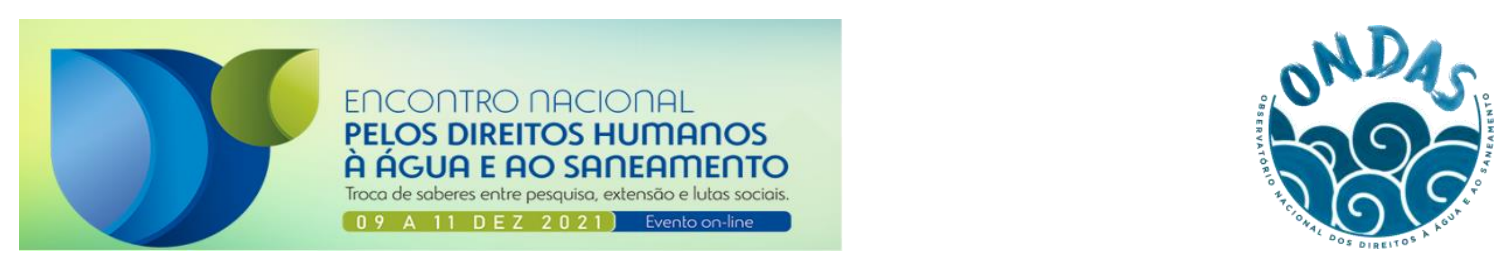

MINISTÉRIO DAS CIDADES. Secretaria Nacional de Saneamento Ambiental. Termo de referência conceitual. Proposta pedagógica da ReCESA. Brasília, 2007.

SANTOS, T. C. C. Implantação de sistemas individuais de esgotos em uma comunidade quilombola na Zona da Mata MG: estudos de concepção e aspectos construtivos. Monografia (Graduação em Engenharia Civil), 2018, 75f. Departamento de Engenharia Civil, Universidade Federal de Viçosa, Viçosa, 2018.

SILVA, B.B. As relações de gênero e o saneamento: um estudo de caso envolvendo três comunidades rurais brasileiras. Dissertação (Mestrado em Saneamento, Recursos Hídricos e Meio Ambiente), 2017, $192 \mathrm{f}$. Universidade Federal de Minas Gerais, Escola de Engenharia, Belo Horizonte, 2017

TÓTOLA, L. A. Levantamento das condições de operação e manutenção e indicações de melhorias em sistemas de tratamento de esgotos domésticos em uma comunidade rural na Zona da Mata - MG. Monografia (Graduação em Engenharia Ambiental), 2018, 54f. Departamento de Engenharia Civil, Universidade Federal de Viçosa, Viçosa, 2020. 